\title{
Practical Teaching Pattern of Digital Signal Processing Course against Backdrop of Electric Power
}

\author{
Sun Zheng \\ Department of Electronic and Communication Engineering \\ North China Electric Power University \\ Baoding, P.R.China \\ sunzheng_tju@163.com
}

\begin{abstract}
This paper explores the reform of classroom teaching and practice of Digital Signal Processing course for undergraduates of electronics and information majors in electric power universities. The reform is based on the features of this course, developing trend of electronic information science and requirement of national electric power construction for professionals. The practice-based teaching is implemented through adjusting teaching content, adopting various teaching methods, strengthening practical training and origin evaluation. The practice includes four levels, that is, computer programming in class, group experiment after class, design-oriented experiment and comprehensive research report. The teaching practice in this mode in our university shows that the teaching quality is improved and students' ability to study, research and practice is developed. The total scores are also improved compared with previous students.
\end{abstract}

Keywords-Specialties of electronic information; Digital signal processing; Teaching reform; Practical teaching

\section{INTRODUCTION}

Digital Signal Processing (DSP) course is one of compulsory professional basic courses for undergraduate students who major in Communication, Electronics, Computer and Information of the full-time higher education. It is a course to further study other professional curriculums after the study of Signal and System course. It focuses on how to use mathematical tools, including advanced mathematics, linear algebra, complex mathematics, probability and statistics, to process and transform signals containing abstract information. It also includes theories and methods of using computer or special equipment to acquire, transform, synthesize, estimate and recognize digital signals. It involves many complicated and abstract mathematical concepts, such as Fourier transform (FT) Laplace transform (LT), $Z$ transformation (ZT) and convolution [1], etc. One of remarkable features of the course is that it is highly theoretical and difficult to learn, and requires students to have a solid mathematical basis and strong application ability. The traditional mode based on teacher teaching in classroom is easy to lead students to feel boring and then lose interest in learning. Moreover, students can not understand abstract theories and algorithms thoroughly, so they may have difficulties to flexibly use the knowledge in future practice, such as graduation project and engineering practice.

The practice-based teaching mode of DSP course is investigated in this paper according to course features, development of the electronics and information specialty in the background of electric power and requirements of the national economic construction on the ability of electronic information personnel. The main guiding ideology is to integrate all the elements needed by the scientific research into the classroom teaching under the guidance of teachers. The teaching activities are organized according to the requirements of scientific research. The course content is combined with practical problems in life, production, or scientific research. As the center of teaching activities, students analyze and solve these problems in the mode of scientific and engineering research with the help of teachers to master knowledge and improve their abilities [2].

This teaching mode requires teachers to design and carry out teaching activities by repositioning curriculum objectives, effectively integrating teaching contents, carefully selecting research topics, rationally assigning tasks of students and scientifically evaluating the achievement of students. Teachers need to fully arouse the positivity and initiative of students to effectively complete teaching tasks specified in the syllabus and realize learning goals. This paper analyzes the advantages and possible problems of applying this teaching mode in DSP course in the background of electric power according to our previous teaching practice and implementation effect.

\section{PRACTICAL TEACHING REFORM}

\section{A. Basic Guidance}

DSP course focuses on basic theories and physical concepts and emphasizes practice and application [3-4]. We reformed the teaching methods through adjusting the teaching content, combining various teaching means, changing the composition of achievements and strengthening the practice. Our purpose is to improve students' learning interest and efficiency, guide students to actively learn instead of passively receiving knowledge. Consequently, students can understand, master and

This work was supported by Project of High Quality Curriculum Construction for Graduate Students of North China Electric Power University. 
apply the theories and research methods to solve practical problems.

\section{B. Adjusting Teaching Content}

The main content of DSP course includes time-domain analysis and frequency-domain analysis of discrete time signals and systems, ZT, discrete Fourier transform (DFT) and its fast algorithms, and design and application of digital filters, etc. It is necessary to properly select and arrange the course content by considering the difficulty of the content and the lack of curriculum hours (48 hours of class teaching and 24 hours of practical experiment in our university). After careful selection, we summarized the main theoretical contents of the course into two parts as shown in Fig. 1.

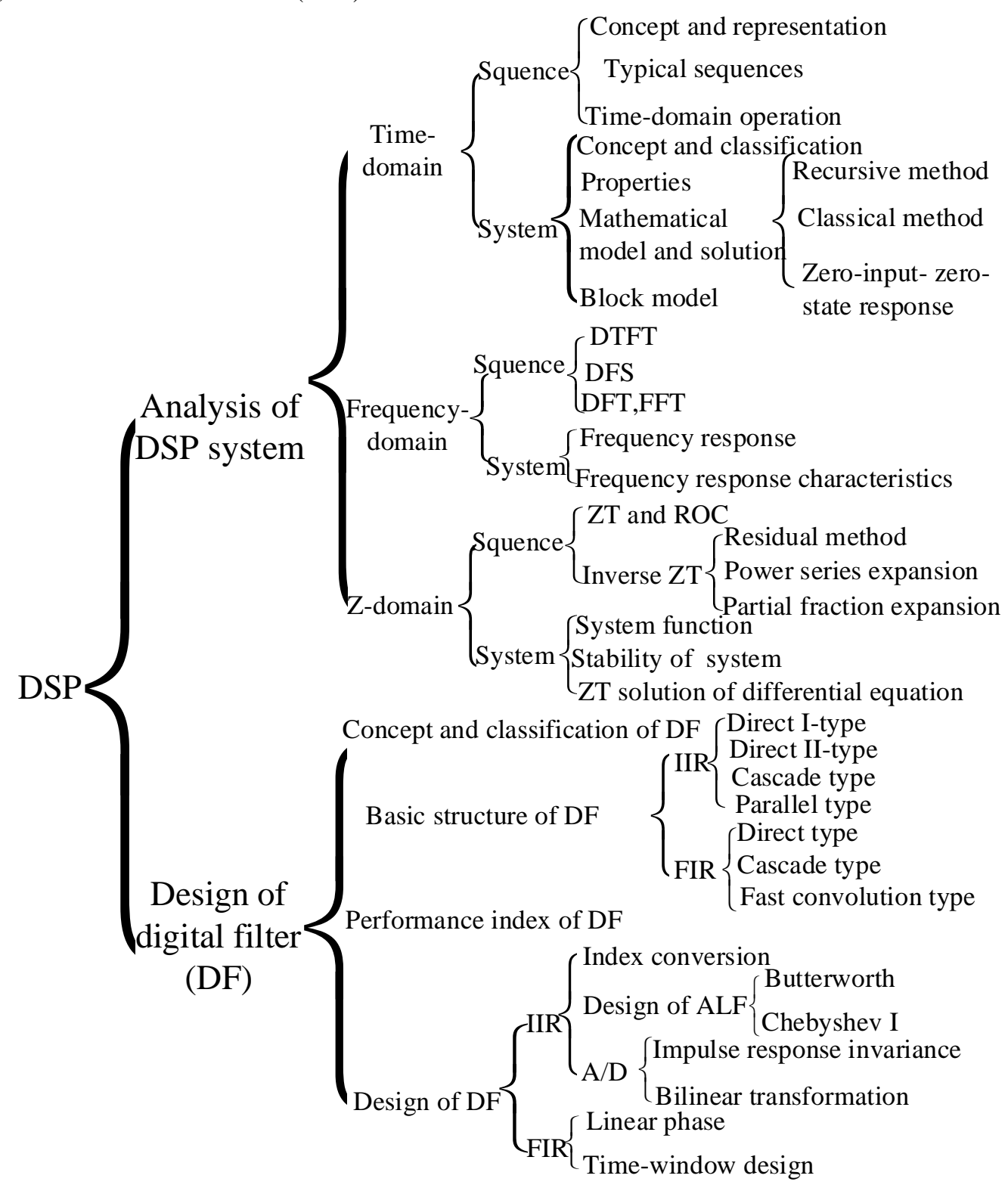

Fig. 1 Knowledge system of DSP course

As a wide-ranging subject, DSP uses mathematical tools including Higher Mathematics, Complex Function, Linear Algebra, Probability and Statistics, etc. Also, it involves professional courses including Circuit and System, Electronic Technology Basis and Signal and System [5]. Hence, students must have a solid mathematical and professional basis before they begin to study this course. The physical concepts of a great deal of theories in this course are described in the form of mathematical deduction. Teachers should pay more attention to students' understanding of the physical meaning contained in the mathematical expressions, rather than simply emphasizing mathematical calculation.

For example, convolution of discrete time signals includes linear convolution, periodic convolution and cyclic convolution. It is very easy to confuse them and difficult to understand the differences and relations between them. Students used to memorize the mathematical formulas by rote and did not understand their physical meaning and function, so they could 
not use them flexibly. In the teaching process, we started from the physical meaning of linear convolution. On the basis of linearity (including superposition and homogeneity), time invariance, unit impulse response and zero-state response of linear time invariant (LTI) systems, the definition of linear convolution was deduced logically as shown in Fig.2. Then, the periodic convolution is essentially the linear convolution of two periodic sequences, where multiplication and addition are only carried out in the main value interval since a periodic sequence can be expressed with its main value sequence and period. Cyclic convolution is a calculation method especially for finite length sequences based on DFT. We explained the relationship between the three types of convolution of two finite length sequences in the form of the proof. In the process of gradual solution, the teacher guided students to draw such conclusions. First, periodic convolution is the periodic extension of linear convolution. Second, cyclic convolution is the main value sequence of periodic convolution. Third, cyclic convolution is the main value sequence of the periodic extension sequence of the result of linear convolution. Furthermore, the properties of cyclic convolution and linear convolution were compared in the form of a table (Table 1). Consequently, students can understand the physical meaning rather than blindly recite the formulas.

TABLE I COMPARISON OF CYCLIC AND LINEAR CONVOLUTION

\begin{tabular}{ccc}
\hline & Cyclic convolution & Linear convolution \\
\hline Physical meaning & Convolution derived from DFT & $\begin{array}{c}\text { The response of a LTI system is the linear } \\
\text { convolution of the emission and the unit } \\
\text { impulse response. } \\
\text { Sequence length }\end{array}$ \\
Length of result sequence & $N_{1}=N_{2}$ & $N_{1}$ and $N_{2}$ can be unequal. \\
$N=N_{1}=N_{2}$ & $N=N_{2}-1$ \\
\hline
\end{tabular}

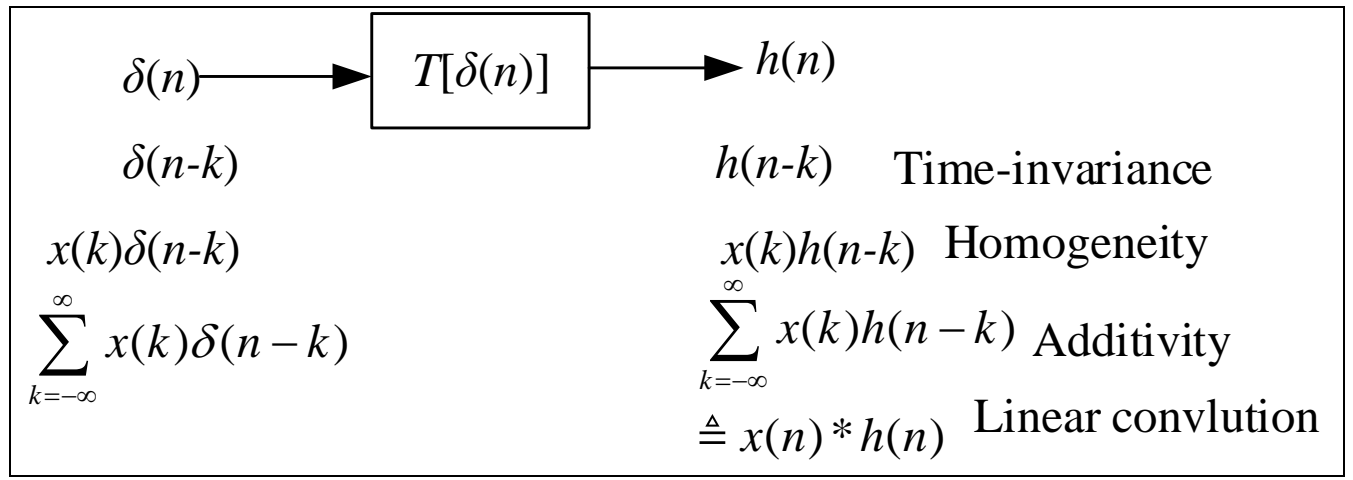

Fig. 2 Physical meaning of linear convolution.

\section{Reforming Teaching Methods}

Various teaching methods including class teaching, programming practice in the class, group experiments after class, project design and seminar were combined. In this way, students can master theories and methods of DSP and apply them to engineering practice.

1) Adopting various teaching methods: In order to improve the effect of multimedia teaching, we still adopted the combination of multimedia and board teaching. The derivation of most formulas and typical examples were all explained in the form writing on the blackboard by the teacher. It is convenient for students to listen, take notes and shorten the time of self-study. The formula which is not very difficult and easy to understand is shown on the multimedia courseware for the teacher to explain in order to make time for students to practice on computers.

Those abstract concepts, such as sampling theorem and frequency response, were explained with PPT courseware with necessary animation for dynamic demos and links which was made with modern multimedia technologies and Matlab [6]. In this way, students can understand the physical meaning clearly from boring mathematical formulas. The teaching effect can be obviously improved.

2) Strengthening practical training: We strengthened practical training by increasing computer programming experiments rather than pay much attention to knowledge and theory. The experiments were designed from easy to difficult, from simple to complex including four levels.

The first level is computer programming in class. Students took their own computers to the classroom and learned basic skills of Matlab software in advance. The teacher designed several typical topics in advance covering the knowledge system listed in Fig.1. In the process of class teaching, after the explanation of a certain knowledge point, students were required to complete corresponding programming problems in classroom.

For example, after the introduction of the definition and features of unit impulse sequence, $\delta(n)$, students were asked to solve the following question by Matlab programming. Use at 
least two methods to generate $\delta(n)$ and draw its waveform. After studying linear convolution, students were asked to complete the following question. Solve $y(n)=h(n)^{*} x(n)$ where $h(n)=R_{8}(n)$ and $x(n)=n R_{16}(n)$ and draw their waveform. For the learning of fast Fourier transform (FFT), the question is as follow. Given $\quad x(n)=\cos (0.48 \pi n)+\cos (0.52 \pi n) \quad$ and $X(k)=\operatorname{DFT}[x(n)]$. Draw the waveform of $x(n)$ and $X(k)$, where (a) $0 \leq n \leq 10$, (b) $0 \leq n \leq 99$ and $x(n)=0$ for $n$ ranges in [11, 99], and (c) $0 \leq n \leq 99$. With three graphic windows, each figure window includes two subgraphs, showing the amplitude of $x(n)$ and $X(k)$, respectively. Compare the three spectrums and explain the difference between the high-density spectrum and high-resolution spectrum.

Through these exercises, students can understand the practical role of a formula, theory, or method in time and intuitively. Also, teachers can know whether students understand the knowledge and correct possible problems in time. At the same time, considering the competition among students, the first finishers formed the pressure for the unfinished ones. It played a role in urging students to study carefully and improved the attendance rate at the same time.

The second level is group experiment after class. After the end of each chapter, we arranged a group experiment. The questions correspond to knowledge points in this chapter. They are a little more difficult than the ones in class practice. According to the list of pupils, three students formed a group to complete a question. The title to be solved of each group is different. After completing the experiment, students wrote the report and returned it in accordance with the time required by the teacher. In addition, a representative of each group presented the contents and design ideas and analyzed the experimental results in class. Each group needed to complete three questions. Three members of the group presented one question each. In this way, every student had the opportunity to present in class. Also, they could have insight into the experiments presented by other groups.

The third level is comprehensive and design-oriented experiment. At the time of teaching progress to $2 / 3$, two comprehensive and design-oriented experiments were arranged every week. The experiments concern about the use of the learned knowledge to solve the problems related to signal processing in electric power engineering practice. For example, spectral analysis and filtering of noisy speech signals, spectral analysis and filtering of digital image signals, filtering of signals generated by electric power equipments, and applying digital filter to decode dual tone multi-frequency signals, etc. The difficulty is much higher than group experiments.

The fourth level is research report. A seminar was arranged in a week before the end of the course. Students could freely select topics in the practical application of DSP in engineering practice according to their interest. They were asked to prepare the research report and PPT presentation in advance from which the teacher chose better ones. Then, the selected students introduced the results of their research or investigation on the seminar. After the introduction, other students or the teacher put forward questions and the students who reported answered them. Moreover, the teacher was responsible to answer and introduce the questions that the students were hard to answer, as well as some other important issues. After discussion, the teacher scored the students according to the representation and discussion.

\section{Reforming Assessment Method}

According to the developing trend of science and technology, we should train professionals majored in electronic information who have not only professional knowledge, but also innovative spirit and practical ability. Therefore, we reformed the method that simply relied on the final examination to evaluate students' learning effect. The assessment of students' learning process, classroom practice, group experiment after class, comprehensive and designoriented experiment and research report were all included in the final scores. So, students recognized that each link is a part of the learning process that can not be ignored. The score of the written final exam with no notes allowed accounted for $50 \%$ of the total score. The questions in the final exam concerned about a flexible use of basic concepts rather than rote memorization of formulas.

\section{ACHIEVEMENTS AND PROBLEMS}

Adopting the above teaching mode, the author has conducted the course of Digital Signal Processing Basis for undergraduates majored in Electronic Information Science and Technology of North China Electric Power University (Baoding) for about three years (2015 2017). The teaching reform has achieved expected results. The students' interest in learning has been obviously improved. Also, the learning effect and the total achievement have been greatly improved compared with previous students especially the ability to use Matlab to program. The students generally reflected that they really learned knowledge and skills in this teaching mode. They even had a deeper and clearer understanding of their specialty.

The existing problem is that students paid too much attention to practical programming, but ignored the ability to solve theoretical problems. For example, they did not pay enough attention to written assignments after class and the accuracy was not high. And the average score of the final exam was slightly lower than in previous years. This course is a necessary subject in National Master's graduate entrance examination of electronic information specialty. So, we still have to balance between theory and practice in the future teaching and strive for achieving a win-win situation. 


\section{CONCLUSION}

Teaching reform is a long-term exploration process. The task of teachers in colleges and universities is to continuously improve the teaching process, improve the teaching quality and cultivate excellent professionals for the national construction. In the previous teaching of DSP course in our university, teachers usually adopted a means of threat, suppression, or even coercion to require students to passively study while neglecting the cultivation of their learning interest and practical ability. Consequently, the results were often counterproductive. Actually, students' learning ability is often different. It is not conducive to the cultivation of students' learning habits and ability if teachers rely on the spoon-feeding and learning by rote.

In the student-centered classroom teaching mode described in this paper, teachers consider the actual situation of every student and teach them the methods of pre-class preview, class study, review after class and practical application according to the difficulty of the knowledge. The enthusiasm of students is consequently aroused. Particularly, the establishment of a research team and the role of the group learning can not be ignored. The traditional class is the class of a few top students who have solid professional knowledge, strong learning initiative and strong ability to accept. They interact well with the teacher in class, and their preparatory work before class and review work after class are well done. Consequently, their learning effect is ideal and then a virtuous circle is formed. Students with poor knowledge and learning disabilities are easily forgotten by the teacher. This creates its own vicious circle that eventually causes these students to be eliminated. Through classroom practice and team cooperation after class, mutual assistance relationship is formed among students. Every student is involved in learning and experiences the pleasure of learning and success. The strength and effort of every student are also fully played, thus the quality of education and teaching is improved.

\section{ACKNOWLEDGMENT}

This work was supported by Project of High Quality Curriculum Construction for Graduate Students of North China Electric Power University.

\section{REFERENCES}

[1] F. Pu, S. Zhao, and S. Wang, "Reform and exploration of research-based teaching of "Digital Signal Processing" course," Computer Education, vol. 7, pp. 81-82, Aug. 2009. (In Chinese)

[2] H. Zhao, S. Zhao, and P. Yu, "On research-oriented teaching model in research-oriented universities," Higher Education of Sciences, vol.15, pp.101-104, June 2007. (In Chinese)

[3] J. Hu and N. Cao, "Exploration of research-typed teaching based on Matlab Digital Signal Processing," China Electric Power Education, vol. 18, pp.67-69, Sep. 2008. (In Chinese)

[4] Y. Huang, "The reformation of the Digital Signal Processing for electrical engineering specialty," Journal of Electrical \& Electronic Education, vol.37, pp.15-17, Jan. 2015. (In Chinese)

[5] Y. Wang, "Discussion of the methods of teaching and learning Digital Signal Process course," Journal of Electrical \& Electronic Education, vol.30, pp.97-98, June 2008. (In Chinese)

[6] J. Guo, "The study of digital signal processing teaching using matlab," Journal of Electrical \& Electronic Education, vol.32, pp.117-119, June 2010. (In Chinese) 